\title{
СОЦИАЛЬНОЕ ЗАКОНОДАТЕЛЬСТВО
}

И.Я. Сенюта

\section{ПРАВА ЧЕЛОВЕКА В СФЕРЕ ОХРАНЫ ЗДОРОВЬЯ: КОНСТИТУЦИОННЫЕ КОНТУРЫ И НОРМОТВОРЧЕСТВО ГРАЖДАНСКОГО ОБЩЕСТВА}

\begin{abstract}
Аннотация. В статье проведен сравнительный анализ законодательства в срере охраны здоровья граждан в Украине и европейской нормативной базы по вопросам защиты прав пациентов. Рассматривается медико-правовой регламент проведения профилактических медицинских вмешательств: вакцинопрофилактики, туберкулинодиагностики. Сопоставляется право на согласие и отказ от выполнения медицинского вмешательства. Анализируются возможности реализации прав граждан на получение доступной, бесплатной и качественной медицинской помощи и запрет любых видов дискриминации по признакам финансовых ресурсов, местожительства, вида заболевания или времени обращения за помощью. Представлена классификация видов медицинской помощи, оказываемой в государственной системе здравоохранения Украины: скорая, амбулаторно-поликлиническая, стационарная, а так же нормативно-правовое обеспечение медицинской деятельности. Подвергнуто анализу право граждан на доступ к информации о своем состоянии и обеспечение конфиденциальности личной информации пациента, как при его жизни, так и после смерти, особенности предоставления медицинской информации членам семьи пациента, в зависимости от состояния пачиента и заключения лечащего врача.

Ключевые слова: Европейская хартия прав пациентов, права пациентов в украинском законодательстве, правовое регулирование здравоохранения в Украине, правовой регламент выполнения медицинских вмешательств, право пациентов на получение информации.
\end{abstract}

$\mathrm{H}$ а современном этапе развития правового регулирования сферы охраны здоровья в Украине особую остроту и актуальность приобретают вопросы защиты прав человека при оказании медицинской помощи. Комплексный анализ национальной нормативно-правовой базы Украины дает возможность выкристаллизовать права пациентов и выявить пробелы законодательства, действующего в этой области. Наиболее детально права пациентов регламентируются Законом Украины «Основы законодательства Украины об охране здоровья» от 19.11.1992 г. (далее Основы), так называемой декларацией прав человека в сфере охраны здоровья. Кроме того, права пациентов могут быть определены на основании норм Конституции Украины от 28.06.1996 г., Гражданского кодекса Украины от 16.01.2003 г. и Клятвы врача, утвержденной Указом Президента Украины от 15.06.1992 г.

Вопросы надлежащего нормативного закрепления прав пациентов, механизмов их реализации ни для международного сообщества, ни для Украины не новы. Анализ зарубежных и национальных научных источников дает основания утверждать, что данная проблематика является одной из наиболее актуальных в сфере медицинского права. Чтобы внести в изложение темы некоторое разнообразие, попытаемся использовать для освещения вопросов, связанных с правами пациентов, Европейскую хартию прав пациентов, принятую Активной общественной сетью в сотрудничестве с общественными организациями 12 стран ЕС (Рим, ноябрь 2002 г.) (далее - Хартия) ${ }^{1}$. Следует подчеркнуть, что, несмотря на свою «квазиюридическую» силу, этот документ широко используется как в нормопроектировании, исследовательской работе, так и в правореализации.

Ключевой конституционной «здравоохранительной статьей» является ст. 49 Конституции Украины, которой предусмотрены разноспектральные права в рамках сферы охраны здоровья: от права на медицинскую помощь до права на доступность медицинского обслуживания. Кроме того, в Основном Законе государства закреплены гарантии возможностей в сфере охраны здоровья. В частности, ч. 2 ст. 49 Конституции Украины предусмотрено, что охрана здоровья обеспечивается государственным финансированием соответствующих социально-экономических, медико-санитарных и оздоровительно-профилактических программ.

Первым правом, определенным в Хартии, является право на профилактические мероприятия: «каждый человек имеет право на надлежащее меди-

Европейская хартия прав пациентов // Медичне право. 2010. - № 6 (II). - C. 56-66. 
цинское обслуживание, направленное на предупреждение заболевания».

Этому праву в украинском законодательстве соответствует право пациента на использование методов профилактики, допустимых к использованию только при условии, что они не могут причинить вреда здоровью больного (ст. 42 Основ). Такой четкой законодательной формулировки данного права, как в Хартии, отечественная нормативно-правовая база не содержит.

Согласно ст. 4 Основ, к принципам здравоохранения относится предупреждающий профилактический подход к охране здоровья. Одним из основных подзаконных документов «профилактического» характера является приказ МЗ Украины «О диспансеризации населения» от 27.08 .2010 г. № 728 , согласно которому дальнейшее развитие и совершенствование профилактического направления здравоохранения, сориентированного на предупреждение заболеваний, охрану и укрепление здоровья каждого гражданина Украины, в значительной степени зависят от успеха диспансеризации населения. Важно отметить, что в данном нормативно-правовом акте соблюдены ключевые права пациента, например, право на согласие на медицинское вмешательство [«медицинский осмотр проводится только с согласия граждан» (абз. 7 п. 2)]; право на свободу выбора врача и учреждения здравоохранения [«диспансеризация проводится учреждениями здравоохранения государственной и коммунальной форм собственности» (п. 3)].

Одним из структурных элементов права на профилактические мероприятия является вакцинопрофилактика. Этот сегмент анализированного права в нашем государстве связан с многочисленными практическими проблемами осуществления и нарушения прав человека.

Для соблюдения прав пациента при осуществлении вакцинопрофилактики следует придерживаться таких нормативных постулатов:

1) профилактические прививки осуществляются в кабинетах прививок, которые создаются как отдельное структурное подразделение больничного и/ или амбулаторно-поликлинического лечебно-профилактического учреждения (далее - ЛПУ) независимо от формы собственности и действуют в лПУ, при медицинских кабинетах дошкольных учреждений, общеобразовательных школ, учебных заведений I-IV уровней аккредитации, медицинских пунктах предприятий;

2) для осуществления вакцинации могут быть привлечены медицинские работники (врач, фельдшер, младший специалист с медицинским образованием), прошедшие специальную подготовку и владеющие навыками организации и техники проведения прививок, туберкулинодиагностики, а также навыками оказания неотложной помощи в случае развития поствакцинальных реакций/поствакцинальных осложнений;

3) перед прививкой или туберкулинодиагностикой обязательно проводится медицинский осмотр;

4) перед проведением вакцинации или туберкулинодиагностики следует получить информированное, добровольное компетентное согласие пациента и/ или его законного представителя. Форму «Информированное согласие и оценка состояния здоровья человека или ребенка одним из родителей или иным законным представителем ребенка на проведение прививки или туберкулинодиагностики» (форма № 063-2 / о) заполняют на всех пациентов, подлежащих прививке или туберкулинодиагностике, независимо от места проживания. Заполненная форма означает, что лицо и/или один из родителей или иной законный представитель ребенка перед прививкой или туберкулинодиагностикой получили полную информацию о процедуре прививки, туберкулинодиагностики, о противопоказаниях к проведению прививки или туберкулинодиагностики, о вакцине и о возможных неблагоприятных последствиях. Совершеннолетним дееспособным гражданам профилактические прививки проводятся с их согласия после предоставления объективной информации о прививке, последствиях отказа от них и возможных поствакцинальных осложнениях. Лицам, не достигшим пятнадцатилетнего возраста или признанным в установленном законом порядке недееспособными, профилактические прививки проводятся с согласия их объективно информированных родителей или иных законных представителей. Лицам в возрасте от пятнадцати до восемнадцати лет или признанным судом ограниченно дееспособными профилактические прививки проводятся с их согласия после предоставления объективной информации и с согласия объективно информированных родителей или иных законных представителей этих лиц;

5) после проведения профилактической прививки и туберкулинодиагностики должно быть обеспечено медицинское наблюдение в течение срока, определенного инструкцией по применению соответствующей вакцины/анатоксина/туберкулина. Если в инструкции по применению вакцины/анатоксина срок наблюдения не указан, лицо, которому была произведена прививка, должно находиться под наблюдением медицинского работника не менее 30 минут после вакцинации;

6) факт отказа от прививок с отметкой о том, что медицинским работником даны разъяснения о последствиях такого отказа, оформляется по форме № 063-2/о, подписывается как гражданином (при 
прививке несовершеннолетних - родителями или иными законными представителями, их заменяющими), так и медицинским работником, о чем следует сообщить в территориальную СЭС;

7) вопрос о посещении дошкольного учебного заведения детьми, родители которых отказываются от прививок, решается врачебно-консультативной комиссией;

8) вопрос о посещении общеобразовательного учебного заведения детьми, не получившими профилактических прививок согласно календарю прививок, решается индивидуально врачебноконсультативной комиссией с привлечением эпидемиолога территориальной санэпидстанции.

Одним из базовых прав с конституционной основой является право на доступность. В Хартии оно интерпретируется как право каждого на доступность медицинских услуг, в которых он/она нуждается по состоянию здоровья. Медицинские службы должны гарантировать равный доступ всем без дискриминации по признакам наличия финансовых ресурсов, местожительства, вида заболевания или времени обращения за помощью. В украинском законодательстве это право определено сквозь призму конституционной гарантии: «государство создает условия для эффективного и доступного для всех граждан медицинского обслуживания» (ч. 3 ст. 49 Конституции Украины).

Определение доступности медицинской помощи содержит Положение о доступности медицинской помощи, принятое ВМА (Вена, сентябрь 1988 г.) $)^{2}$. Это многогранное понятие представлено как баланс многих факторов в рамках жестких практических ограничений, обусловленных ресурсами и возможностями государства. К таким факторам принадлежат кадры, финансирование, транспортные средства, свобода выбора, общественная грамотность населения, качество и распределение технических ресурсов. Баланс именно этих элементов определяет степень доступности общей медицинской помощи населению.

Согласно Положению, наибольшая доступность обеспечивается при следующих условиях: 1) каждому доступна необходимая ему медицинская помощь (т. е. отсутствуют ограничения физического или временного характера); 2) обеспечена максимальная свобода выбора исполнителей, системы оказания помощи и системы оплаты, удовлетворяющая различные потребности населения; 3) информированность, обучение и образованность населения по всем элементам, касаю-

\footnotetext{
2 Положення про доступність медичної допомоги, прийняте 40-ю Всесвітньою медичною асамблеєю, Відень, Австрія, вересень 1988 року // Права людини в системі взаємовідносин «лікар-пацієнт» в відкритому суспільстві. - К.: Медицина України, 2000. - С. 81-83.
}

щимся доступа к помощи; 4) адекватное участие всех сторон в разработке и управлении системами.

Как видно из определения права на доступность в международном стандарте, это право «многоаспектное», т. е. включает, например, право на защиту от любых незаконных форм дискриминации, связанных с состоянием здоровья, право на бесплатную медицинскую помощь, право на свободу выбора в сфере охраны здоровья.

Характеризуя эту возможность, сфокусируем внимание на праве на бесплатную медицинскую помощь. Согласно национальному законодательству его можно назвать "правом-фикцией», так как формальная конституционная возможность фактически не соблюдается. Основной Закон государства содержит норму-гарантию: «в государственных и коммунальных учреждениях здравоохранения медицинская помощь предоставляется бесплатно» (ч. 3 ст. 49). Конституционный Суд Украины в Решении по делу согласно конституционному представлению 53 народных депутатов Украины об официальном толковании положения ч. 3 ст. 49 Конституции Украины «в государственных и коммунальных учреждениях здравоохранения медицинская помощь предоставляется бесплатно» (дело о бесплатной медицинской помощи) от 29.05.2002 г. (далее - Решение КСУ 2002 г.) указал, что положение ч. 3 ст. 49 Конституции Украины «в государственных и коммунальных учреждениях здравоохранения медицинская помощь предоставляется бесплатно» следует понимать так, что в государственных и коммунальных учреждениях здравоохранения медицинская помощь предоставляется всем гражданам независимо от ее объема и без предварительного, текущего или последующего ими расчета за предоставление такой помощи.

Иностранцам и лицам без гражданства, временно пребывающим на территории Украины, медицинская помощь, в том числе экстренная, предоставляется за плату, если законодательством или международными договорами Украины не предусмотрено иное, согласно Постановлению Кабинета Министров Украины «Об утверждении Порядка предоставления медицинской помощи иностранцам и лицам без гражданства, временно пребывающим на территории Украины, и признании утратившими силу некоторых постановлений Кабинета Министров Украины» от 22.06.2011 г. № 667.

В ч. 1 ст. 3 Закона Украины «Об экстренной медицинской помощи» (вступает в силу с 01.01.2013г.) предусмотрено, что на территории Украины каждый гражданин Украины и любое иное лицо имеют право на бесплатную, доступную, своевременную и качественную экстренную медицинскую помощь. Как следует из буквального толкования данного положения 
Закона, субъектами, имеющими право на бесплатную экстренную медицинскую помощь, являются не только граждане Украины, но и любые другие лица, т. е. и иностранные граждане, и лица без гражданства. В ч. 2 ст. 3 этого Закона указано, что иностранцы и лица без гражданства, временно находящиеся на территории Украины, обеспечиваются экстренной медицинской помощью в порядке, определенном Кабинетом Министров Украины. В данной части статьи Закона речь идет об оговорке относительно временных границ пребывания иностранцев и лиц без гражданства на территории Украины, т. е. на платной основе экстренная медицинская помощь оказывается только при условии, что субъект находиться на территории государства временно, согласно п. 1 Постановления Кабинета Министров Украины «Об утверждении Порядка предоставления медицинской помощи иностранцам и лицам без гражданства, временно пребывающим на территории Украины, и признании утратившими силу некоторых постановлений Кабинета Министров Украины» от 22.06.2011 г. № 667.

На законодательном уровне определен перечень услуг, бесплатное предоставление которых в государственных учреждениях здравоохранения не может гарантировать государство. К ним относится медицинский осмотр лиц: 1) для получения удостоверения водителя транспортных средств; 2) для получения разрешения на право получения и ношения оружия гражданами, за исключением военнослужащих и должностных лиц, разрешение на ношение оружия которым предусмотрено законодательством; 3) для получения соответствующих документов на выезд граждан за границу по вызову родственников, проживающих в зарубежных странах; 4) для получения соответствующих документов на оздоровление в зарубежных лечебных или санаторных учреждениях по собственному желанию; 5) для получения соответствующих документов на служебные командировки, за исключением государственных служащих, работа которых связана с такими выездами и которые имеют соответствующие медицинские документы.

Параллельно Решению КСУ 2002 г., в юридической плоскости расположена Программа предоставления гражданам гарантированной государством бесплатной медицинской помощи, утвержденная постановлением Кабинета Министров Украины от 11.07.2002 г. № 955. В ст. 2 Постановления определено, что государственными и коммунальными учреждениями здравоохранения предоставляется бесплатная медицинская помощь таких видов: 1) скорая и неотложная - на догоспитальном этапе станциями (отделениями) скорой медицинской помощи, пунктами неотложной медицинской помощи в состоянии, угрожающем жизни человека; 2) амбулаторно-поликлиническая; 3) стационарная - в случае острого заболевания и в неотложных случаях, когда необходимы интенсивное лечение, круглосуточный медицинский надзор и госпитализация, в том числе по эпидемическим показаниям, детям, беременным и роженицам, больным по направлениям медикосоциальных экспертных комиссий, врачебно-консультативных комиссий; 4) неотложная стоматологическая помощь (в полном объеме - детям, инвалидам, пенсионерам, студентам, беременным, женщинам, имеющим детей до 3 лет); 5) доврачебная медицинская помощь сельским жителям; 6) санаторно-курортная помощь инвалидам и больным в специализированных и детских санаториях; 7) содержание детей в домах ребенка; 8) медико-социальная экспертиза потери трудоспособности. Это Постановление, конечно же, противоречит положениям Основного Закона Украины, Решению КСУ 2002 г., но неконституционным оно не признано, вследствие чего в пространстве «бесплатности» присутствует нормативная коллизия. На практике этот вопрос решается с помощью принципа иерархии нормативно-правовых актов.

Важным вопросом сферы охраны здоровья является оборот информации, что обусловлено как правосубъектной составляющей этого процесса, так и многочисленными изменениями законодательства в этом контексте.

В соответствии со ст. 3 Хартии, каждый имеет право на получение любой информации о состоянии своего здоровья, о медицинских услугах (и способах получения этих услуг), а также обо всем, что доступно благодаря научно-техническому прогрессу. Конституционной основой этого права является ст. 34 Основного Закона государства, в которой указано, что «каждый имеет право свободно собирать, хранить, использовать и распространять информацию устно, письменно или иным способом - по своему выбору».

Право на информацию в украинском законодательстве обозначено как право на информацию о состоянии своего здоровья, гарантированное ст. 285 Гражданского кодекса Украины, п. «е» ст. 6, 39 Основ. В частности, в ст. 39 Основ указывается, что пациент, достигший совершеннолетия, имеет право на получение достоверной и полной информации о состоянии своего здоровья, в том числе на ознакомление с соответствующими медицинскими документами, касающимися его здоровья (ч. 1). Родители (усыновители), попечитель, опекун имеют право на получение информации о состоянии здоровья ребенка или подопечного (ч. 2).

В контексте этого права целесообразно проиллюстрировать регламентацию анализируемой возможности с помощью ещё одного регулятора - моральнодеонтологического. Этический кодекс врача Украины, утвержденный на Всеукраинском съезде врачебных организаций и X Съезде Всеукраинского врачебного 
общества от 27.09.2009 г. ${ }^{3}$, в п. 3.7. предусматривает, что пациент имеет право на исчерпывающую информацию о состоянии своего здоровья, но может от нее отказаться или определить лицо, которому можно сообщать о состоянии его здоровья. Информация может быть скрыта от пациента в тех случаях, если имеются весомые основания считать, что она может нанести ему серьезный ущерб. Тем не менее, в случае настойчивого требования пациента врач обязан предоставить ему исчерпывающую информацию. В случае неблагоприятного для больного прогноза необходимо проинформировать его деликатно и осторожно, оставив надежду на продолжение жизни, возможный благоприятный исход.

При осуществлении права на медицинскую информацию на практике возникает много вопросов правореализационного характера, которые решаются не всегда однозначно. Прежде всего, следует обратить внимание на понятийный аппарат составляющих этого права.

В Решении Конституционного Суда Украины по делу относительно официального толкования ст. 3, 23, 31, 47, 48 Закона Украины "Об информации» и ст. 12 Закона Украины «О прокуратуре» (дело К. Г. Устименко) от 30.10.1997 г. (далее - Решение КСУ 1997 г.) определено, что медицинская информация - это сведения о состоянии здоровья человека, истории его болезни, о цели предложенных исследований и лечебных мероприятий, прогноз возможного развития заболевания, в том числе о риске для жизни и здоровья, по своему правовому режиму является конфиденциальной. Анализ нормы ч. 3 ст. 39 Основ дает основания утверждать, что положение экстраполировано с упомянутого решения Конституционного Суда Украины в понятийный аппарат права, изложенного в законе, сквозь призму обязанности врача о предоставлении медицинской информации.

Комплексный подход к исследованию права на медицинскую информацию согласно национальному законодательству дает возможность сформулировать некоторые замечания:

1. Возрастным цензом для реализации права на медицинскую информацию является достижение совершеннолетия.

2. Объем предоставления медицинской информации членам семьи пациента зависит от следующих условий:

2.1. Если пациент жив и в состоянии реализовать свои права.

3 Етичний кодекс лікаря України, прийнятий та підписаний на Всеукраїнському з'їзді лікарських організацій та X 3’їзді Всеукраїнського лікарського товариства в м. Євпаторія 27.09.2009 р. // Медичне право. - 2010. - № 5 (I). - С. 115-123.
При условии, что пациент жив, действующее законодательство регламентирует вопрос надлежащим образом в аспекте п. 2 ст. 285 Гражданского кодекса Украины и ч. 2 ст. 39 Основ относительно права родителей (усыновителей), опекунов, попечителей на информацию о состоянии здоровья ребенка или подопечного. С целью сохранения права человека на медицинскую тайну считается правильным предоставлять членам семьи медицинскую информацию о пациенте, если он жив, только с его согласия. Конечно же, это должно стать общим правилом, исключения из которого нужно четко определить в законодательном порядке. Поэтому положение Решения КСУ 1997 г., согласно которому врач обязан, по требованию пациента, членов его семьи, предоставить им медицинскую информацию полностью и в доступной форме, должно быть корректным в аспекте обязанности врача на предоставление информации по требованию членов семьи пациента или в случае смерти пациента, или при согласии пациента, или на основании нормативно установленных исключений, без согласия лица.

\section{2. В случае смерти пациента.}

В случае смерти физического лица члены его семьи или иные уполномоченные ими физические лица имеют право присутствовать при расследовании причин его смерти и ознакомиться с выводами о причинах смерти, а также право на обжалование этих заключений в суде (п. 4 ст. 285 Гражданского кодекса Украины и ч. 5 ст. 39 Основ). Речь идет о праве членов семьи пациента после смерти ознакомиться, но с четко определенным объемом медицинской информации. Учитывая принцип аналогии закона, потребность защиты прав правопреемников умершего пациента (например, относительно права на возмещение морального вреда, гарантированного 4. 2 ст. 1168 Гражданского кодекса Украины), в запросе о доступе к персональной информации следует оговаривать необходимый для заявителя объем медицинской информации (не ограничиваясь четко нормативно закрепленными сведениями), с соответствующей мотивацией.

3. Для реализации пациентом права на ознакомление с соответствующими медицинскими документами следует использовать нормативные гарантии, определенные Законом Украины «О защите персональных данных», наряду с положениями, закрепленными в ч. 1 ст. 285 Гражданского кодекса Украины, ч. 1 ст. 39 Основ. При условии обращения пациента или его представителя по закону или договору в установленном законодательством порядке субъект имеет право на получение персональных данных. В данном случае необходимо подготовить запрос о доступе к персональным данным и направить его владельцу базы персональных данных, которыми являются учреждения здравоохранения всех 
форм собственности, согласно ст. 2, ч. 2 ст. 4 Закона Украины «О защите персональных данных».

4. Медицинский работник имеет право ограничить объем предоставления медицинской информации в особых случаях, если полная информация может нанести ущерб здоровью пациента (п. 3 ст. 285 Гражданского кодекса Украины, ч. 4 ст. 39 Основ, Решение КСУ 1997 г.). Законодатель такие случаи не предусмотрел, но из теории медицинского права вытекает, что к ним можно отнести либо определенные заболевания (в частности, онкологию), либо определенное состояние пациента (в частности, неподдающееся лечению).

Характеристика прав пациентов, основанная на Европейской хартии прав пациентов и на национальном законодательстве, обеспечивает возможность научным сотрудникам и практикам от медицины и права выявить пробелы и недостатки украинского законодательства, определить основные направления совершенствования нормативно-правовой базы в сфере охраны здоровья, как одной из приоритетных сфер адаптации законодательства Украины к законодательству Европейского Союза [раздел V Закона Украины «Об Общегосударственной программе адаптации законодательства Украины к законодательству Европейского Союза» (18.03.2004)]. Хартия, учитывая её значение в мировом сообществе, многовекторность имплементации её положений в законодательную базу, утверждает гражданское общество как равноправного участника нормотворческого процесса государства.

\section{Библиографический список:}

1. Европейская хартия прав пациентов // Медичне право. - 2010. - № 6 (II). - С. 56-66.

2. Положення про доступність медичної допомоги, прийняте 40-ю Всесвітньою медичною асамблеєю, Відень, Австрія, вересень 1988 року // Права людини в системі взаємовідносин «лікар-пацієнт» в відкритому суспільстві. - К.: Медицина України, 2000. - С. 81-83.

3. Етичний кодекс лікаря України, прийнятий та підписаний на Всеукраїнському з'їзді лікарських організацій та X 3'їзді Всеукраїнського лікарського товариства в м. Євпаторія 27.09.2009 р. // Медичне право. - 2010. - № 5 (I). - C. 115-123.

\section{References (transliteration):}

1. Yevropeyskaya khartiya prav patsiyentov // Medichne pravo. - 2010. - № 6 (II). - S. 56-66.

2. Polozhennya pro dostupníst' medichnoï dopomogi, priynyate 40 -yu Vsesvítn'oyu medichnoyu asambleêyu, Víden', Avstríya, veresen' 1988 roku//Prava lyudini v sistemí vzaêmovídnosin "líkar-patsiênt» v vídkritomu suspíl'ství. K.: Meditsina Ukraïni, 2000 - S. 81-83.

3. Yetichniy kodeks líkarya Ukraîni, priynyatiy ta pídpisaniy na Vseukraïns'komu z'ízdí líkars'kikh organízatsíy ta KH Z'ïzdí Vseukraïns'kogo líkars'kogo tovaristva v m . Êvpatoríya 27.09.2009 r. // Medichne pravo. - 2010 - № 5 (YA). S. $115-123$. 